\title{
Emotional intelligence: a place in public health promotion and education
}

\author{
Amir Bhochhibhoya and Paul Branscum* \\ *Correspondence: pbranscum@ou.edu

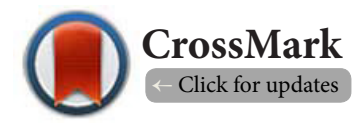

Department of Health and Exercise Science, The University of Oklahoma, Oklahoma 73019, USA.

\begin{abstract}
Researchers have long been interested in traditional forms of intelligence for predicting personal and profession life successes, however such dimensions have not been largely successful as they oftentimes miss the social component of human interaction. To capture this absence, researchers have proposed a new type of intelligence, which has been coined emotional intelligence. The purpose of this article was to provide a brief review how concepts of emotional intelligence have emerged in the previous 30 years, and to discuss the potential application emotional intelligence has in public health research and practice. This article will review three proposed models of emotional intelligence (ability, personality, and mixed), with corresponding measurements. In addition, the current state of research on how emotional intelligence has been related with risk factors related to the most prevalent chronic diseases will be summarized. Suggestions for future research and practice are presented.
\end{abstract}

Keywords: Emotional intelligence, public health, health promotion, social intelligence

\section{Background}

At the beginning of the $20^{\text {th }}$ Century, researchers captivated by the potential for new classes of intelligence beyond traditional forms such as mechanical, verbal, and analytical. Assessments of traditional types of intelligence were sufficient to evaluate an individual's ability to understand how the physical world worked, to be proficient in using vocabulary, and to retain information, but the social components of human interaction were largely missed. Early on Edward Thorndike, a distinguished researcher in psychology and biology, introduced the term "Social Intelligence" [1]. Social intelligence was defined as the ability to understand people and act wisely in human relations [2]. Social intelligence incorporated the social elements of human interaction, and can be considered the earliest version of emotional intelligence.

Later, Edward Gardner introduced the Theory of Multiple Intelligence by differentiating intelligence into seven specific sensory abilities, or types of intelligence: logical-mathematical, linguistic, musical, spatial, bodily-kinesthetic, interpersonal, and intrapersonal [3]. Interpersonal and intrapersonal intelligence highlighted the major emotions towards self and in social interactions. In 1985, Wayne Payne coined the word emotional intelligence (EI) in his dissertation, which was closely associated with Gardner's classification of interpersonal and intrapersonal intelligence [4]. Wayne Payne was also known as the first educator to introduce emotional intelligence in academic research. He developed a theoretical and conceptual framework to conduct research, and further understand the concept and characteristics of human emotion. Later Mayer and Salovey developed a method of evaluating an individual's emotional ability by introducing the Mayer-Salovey-Cruso Emotional Intelligence Test (MSCEIT) [5]. In 1994, a science journalist named Daniel Goleman wrote the book 'Emotional Intelligence', which presented the concepts of emotional intelligence to the general public. His application of emotional intelligence was to primarily help individuals overcome bad habits, develop positive habits, and take control over one's own behavior [6].

\section{Defining emotional intelligence}

The concept of emotion is universally known, but operationalizing and applying emotion for scientific investigation can be difficult. Emotional intelligence has been a concept for 3 decades, but is still only emerging in the academic setting. It has been theorized in various ways and at times has created confusion among researchers, due to the numerous definitions and conceptual frameworks [7]. In addition, many instruments have been designed and introduced to evaluate emotional intelligence. Therefore, a common understanding or a unified 
Bhochhibhoya et al. Paediatrics and Health 2015,

http://www.hoajonline.com/journals/pdf/2052-935X-3-2.pdf

doi: $10.7243 / 2052-935 X-3-2$

direction towards identifying and operationalizing standard constructs to measure emotional intelligence has yet to be established [8]. Currently, there are three major El models: the ability model, the personality model, and the mixed model. Most of today's research on emotional intelligence follows one of these models, which are presented in the following section.

\section{Ability model}

After "Emotional Intelligence" was first coined in 1960 [9], Salovey and Mayer [10] explicitly defined emotional intelligence by dividing it into a model with four major constructs, including one's ability to perceive emotions, utilize emotions, regulate emotions, and manage emotions [11]. This model is commonly referred to as the Mayer and Salovey's Ability model. The first construct of the model includes the ability a person has with understanding nonverbal reception of and expression of emotions which includes interpretation of body language, facial expressions, and tone of voice. The second construct includes the ability to think intellectually, rationally, and logically and to make better decisions to evaluate different perspectives based on emotional cues [11]. The third constructis the ability individuals have to channel or modify an emotional reaction to situations, such as denying, masking, and curtailing [12]. The final construct of this model is the ability to identify emotions, interpret emotions accurately, understand complex feelings that result from emotions, and to control or redirect self-impulsive thoughts and moods towards having a positive attitude. The final construct of this model also encompasses attitudes such as comfort with ambiguity, openness to change, and trustworthiness $[11,13]$.

\section{Personality model}

David Goleman, another prominent researcher in the area of emotional intelligence, introduced the Personality Model of Emotional Intelligence. The Personality Model contained five major domains: self-awareness, managing personal emotions, self-motivation, empathy, and handling external relationships [6]. He defined self-awareness as an individual's ability to recognize one's emotions as they occur. Managing personal emotions were defined as how one can handle emotions in a fashion that further builds self-awareness. Self-motivation includes the ability to channel emotions for the achievement of a specific goal. Empathy is to recognize and appreciate emotions other people are experiencing. Finally, handling external relationships is the ability to manage emotions with the goal of establishing better relationships with others.

\section{Mixed model}

The final model in this review is the Mixed Model of emotional intelligence introduced by Reuven Bar-On [14] which focused on the importance of emotional expression and the result of emotional and social behaviors. His model has deep roots in Darwin's early work on the significance of emotion for survival and adaptation, as well as Thorndike's view of the importance of social intelligence and its importance on human performance. His model contains five components: the ability to identify, comprehend and express emotions and feeling; the ability to understand how others feel and empathize with their feelings; the ability to manage and regulate emotions; the ability to manage change, to adapt, and to solve problems of both a personal and interpersonal nature; and the ability to generate positive affect and be self-motivated [15]. A summary of all three models, with respective evaluation tools, is presented on Table 1.

\section{Why use emotional intelligence in public health and health promotion?}

Constructs of emotional intelligence, such as the ability to understand, regulate, and perceive emotions, can contribute to the promotion of mental, social and physical health [16]. Emotions are a motivating factor that can initiate, sustain, and direct human behavior [17]. Emotions can provide motivation for people to act or not to act. For example, people enact behaviors that make them happy, but also avoid behaviors that they anticipate will make them feel unhappy. People also want to be loved by others, and to be socially accepted. Emotional intelligence helps researchers conceptualize human emotions, which would be an important contribution to the field of public health, as researchers and practitioners can use this information to better predict and change health related behaviors. One of the core interests of public health is to enhance the quality of life for defined populations.

Table 1. A summary of emotional intelligence models.

\begin{tabular}{llll}
\hline & Ability model & Personality model & Mixed model \\
\hline Theoretical framework & Salovey \& Mayer, (1990) & Goleman (1995) & Bar-On (1997) \\
\hline Constructs & 1. Perceiving emotions & 1. Self- awareness & 1. Intrapersonal \\
& 2. Utilizing emotions & 2. Managing personal emotions & 2. Interpersonal \\
& 3. Regulating emotions & 3. Self-motivation & 3. Adaptability to stress \\
& 4. Managing emotions & 4. Empathy & 4. General mood \\
& & 5. Handling external relationship & \\
\hline Assessment instrument & 1. Mayer-Salovey-Caruso Emotional & Emotional and Social Competence Emotional Quotient & Inventory (EQ-i) \\
& Intelligence Test (MSCEIT) & Inventory (ESCI) & \\
& 2. Schutte Self Report Emotional & & \\
& Intelligence Test (SSEIT) & & \\
\hline
\end{tabular}


Quality of life is oftentimes enhanced by promoting lifestyle behaviors with known relationships to communicable and non-communicable diseases and conditions. For example, at the community level, commonly promoted lifestyle behaviors include adopting higher levels of physical activity and avoiding tobacco and heavy use of alcohol. In this context, studying emotional intelligence in public health and health promotion could help to enhance future lifestyle interventions.

\section{Emotional intelligence: a place in public health promotion and education}

Little research has been published to date on how emotional intelligence can be useful in the field of public health and health promotion. Recent meta-analyses have indicated that overall emotional intelligence can be a promising factor in predicting various life outcomes, including personal health [16]. Emotional intelligence has also been noted as a plausible predictor of health [18]. While several challenges in public health and health promotion currently exist, the increased prevalence of chronic diseases is oftentimes noted as the most critical for today's society. In the U.S., it has been estimated that $75 \%$ of money spent on health care is attributable to the management of chronic diseases [19]. Four behaviors strongly associated with the etiology of chronic diseases are tobacco use, physical inactivity, unhealthy eating behaviors, and excessive drinking. The following provides a brief review of instances emotional intelligence has been studied with each behavior.

\section{Tobacco use}

Tobacco use is the most important preventable health issue in the United States [20]. According to the U.S. Department of Health and Human Services [21,22], more than 480,000 deaths occur related to smoking annually. Due to peer pressure and tobacco related advertisements adolescents are especially a vulnerable group for tobacco addiction. Adolescents are also more sensitive to nicotine addiction compared to adults [21]. Approximately 9 out of 10 current smokers started smoking before 18 years and of that population $99 \%$ started by age of 26 [21]. The U.S. Department of Health and Human Services also estimated that if current rates of smoking persist, one in every 13 American younger than 17 years old will die prematurely from smoking related diseases, such as lung disease, cancer, and cardiovascular disease [21]. Previous studies have reported a strong positive relationship between adolescents' tobacco use with stress, anxiety, depression, low self-esteem, and aggressive behavior [21]. For this review only two studies were found that have explored the association between emotional intelligence and adolescent smoking. One study done with students in the $7^{\text {th }}$ and $8^{\text {th }}$ grade found that students with a lower emotional intelligence were two times more likely to engage in smoking behaviors [23]. Another study suggested that high levels of emotional intelligence buffers the effects of various smoking risk factors on future intentions for smoking [24]. In the same study, researchers also suggested that high emotional intelligence was related to adolescent's confidence to refuse offers for cigarettes from others. Emotional intelligence studies in the area of preventing smoking are at an early stage, however, current studies suggest that accounting for novel constructs of emotional intelligence in future interventions may lead to increased effectiveness by buffering effects several smoking risk factors $[\mathbf{2 3}, \mathbf{2 4}]$.

\section{Physical activity}

Physical activity contributes to overall health and the prevention of a number of chronic diseases, and has been associated with lower risk of depression, hypertension, diabetes, and certain cancers [25-27]. Despite the known benefits of physical activity however, less than half of the U.S. adult population (48\%) meets current physical activity guidelines established by the U.S. Department of Health and Human Services (HHS) [28]. Similarly, only 3 out of 10 high school students report engaging in at least 60 minutes of physical activity per day. Few studies have explored the relationship between emotional intelligence and physical activity and results from these studies have been mixed. Two studies conducted outside the U.S found a positive relationship between emotional intelligence and physical activity. One study conducted among a sample of Taiwanese college students reported participation in physical activity might be an effective way to improve emotional health of college students [29]. Another study conducted among support staff in Malaysia reported significant differences for emotional intelligence among the high, moderate, and lower physically active groups for both men and women[30]. The only known study conducted in the United States to explore emotional intelligence and physical activity among college students suggested emotional intelligence may not be an effective predictor of physical activity behaviors [31]. These exploratory studies reflect mostly a positive correlation between emotional intelligence and levels of physical activity. Future research in this area can seek the causal relationship between emotional intelligence and physical activity.

\section{Unhealthy eating behaviors}

Unhealthy eating behaviors are one of many causes for obesity. More than one third of the U.S. population is considered obese, along with $17 \%$ of children and adolescents (age 2-19). Emotional states and situations have been noted to affect food intake, which can lead to emotional eating or consuming food driven by positive or negative emotional states, in the absence of physical hunger [32]. For example, one study reported that during negative emotional situations a sample of overweight adults over-consumed calories, while a sample that was underweight tended to under-consume calories [33]. Another study found that emotional eating was a significant predictor of binge-eating disorder [34]. While studies have explored emotional eating as a risk factor for obesity, bingeeating disorder, and stress, no studies to date have explicitly 
Bhochhibhoya et al. Paediatrics and Health 2015,

http://www.hoajonline.com/journals/pdf/2052-935X-3-2.pdf

doi: $10.7243 / 2052-935 X-3-2$

explored how emotional intelligence is related to unhealthy eating behaviors. These studies can provide the basis for future research to study relationship between emotional intelligence and unhealthy eating.

\section{Excessive drinking}

The Center of Diseases Control and Prevention estimates approximately 88,000 deaths occur each year related to excessive drinking [35]. Chronic diseases resulting from excessive alcohol drinking include liver problems, cardiovascular problems, and increased risk for various cancers [36,37]. College students are at an especially high risk for excessive drinking and alcohol abuse. Most college students drink alcohol (80\%) and half engage in binge drinking behaviors [38]. Studies have linked excessive drinking with depression [39] and stress [40]. Three studies were found that have explored the relationship between alcohol use and emotional intelligence. A study conducted by Qualter and colleagues [41] reported that youth with a high level of emotional intelligence had a low likelihood for drinking alcohol and smoking cigarettes. Another study by Claros and Sharma [42] reported lower emotional intelligence was a key predictor of alcohol use. The third study conducted by the same authors, suggested that emotional intelligence may be predictive of poor adjustment and negative life outcomes such as excessive alcohol consumption [43]. More research in this area will be helpful in understanding how emotional intelligence can be integrated in future intervention to reduce excessive drinking.

\section{Conclusions}

Emotional intelligence is an emerging concept for understanding mental health and human behaviors. A universal definition and a standard evaluation scale for emotional intelligence have yet to be finalized. However, the importance of emotional intelligence for health promotion cannot be overlooked. For example, uncontrolled emotions towards situations can lead to stress, and can result in certain physiological change such as hypertension. While advances in science and technology have established objective measures for blood pressure, such measures do not exist for psychosocial traits and constructs such as stress or emotions. This should not discourage researchers from measuring such variables, however it is also the harsh truth that this is likely limiting mental health variables from being an acceptable indicator of overall health and quality of life.

The purpose of this brief review was to bring light to the concept of emotional intelligence and to suggest ways in which it can be used for public health and health promotion practice and research. There have been an increase in the number of studies on emotional intelligence and mental health, however, there is a noted lack of studies that have explored emotional intelligence and health related behaviors, especially those behaviors known to be risk factors for chronic diseases. Some research has started to emerge on this matter, but the evidence for its application is still in its early stages. Through understanding human emotion by using emotional intelligence, various questions related with public health and health promotion might be answered.

\section{Competing interests}

The authors declare that they have no competing interests.

Authors' contributions

\begin{tabular}{|l|c|c|}
\hline Authors' contributions & AB & PB \\
\hline Research concept and design & $\checkmark$ & $\checkmark$ \\
\hline Collection and/or assembly of data & -- & -- \\
\hline Data analysis and interpretation & -- & -- \\
\hline Writing the article & $\checkmark$ & $\checkmark$ \\
\hline Critical revision of the article & $\checkmark$ & $\checkmark$ \\
\hline Final approval of article & $\checkmark$ & $\checkmark$ \\
\hline Statistical analysis & -- & -- \\
\hline
\end{tabular}

Publication history

Editor: Philip Rosenthal, University of California, USA.

Senior Editor: Victor C. Strasburger, UNM School of Medicine, USA. Received: 25-Nov-2014 Final Revised: 15-Apr-2015

Accepted: 04-May-2015 Published: 11-May-2015

\section{References}

1. Thorndike E. L. Intelligence and its uses. Harper's Magazine. 1920; 227235.

2. Sternberg R. J and Smith C. Social intelligence and decoding skills in nonverbal communication. Social Cognition. 1985; 3:168-192. | Article

3. Gardner H. E. Frames of Mind: The Theory of Multiple Intelligences. New York, NY: Basic books. 1985.

4. Payne W. L. A study of emotion: Developing emotional intelligence; self-integration; relating to fear, pain and desire. Dissertation Abstracts International. 1986; 47. | $\underline{\text { Article }}$

5. Mayer JD, Salovey P, Caruso DR and Sitarenios G. Measuring emotional intelligence with the MSCEIT V2.0. Emotion. 2003; 3:97-105. | Article | PubMed

6. Goleman D. Emotional Intelligence: Why It Can Matter More Than IQ. New York, NY: Bantam. 2006. I Website

7. Emmerling R. J and Goleman D. Emotional intelligence: Issues and common misunderstandings. Issues in Emotional Intelligence. 2003; 1:1-32. | Article

8. Locke E. A. Why emotional intelligence is an invalid concept. Journal of Organizational Behavior. 2005; 26:425-431. | Article

9. Ghent D. B. The English Novel, Form and Function. New York, NY: Harper. 1961. I Website

10. Salovey $\mathrm{P}$ and Mayer J. D. Emotional intelligence. Imagination, Cognition and Personality. 1990; 9:185-211. | Pdf

11. Mayer J. D and Salovey P. What is emotional intelligence? In P. Salovey \& D. Sluyter (1 ${ }^{\text {st }}$ Eds.), Emotional Development and Emotional Intelligence: Implications for Educators. New York, NY: Basic. 1997. | Pdf

12. Gross JJ. Emotion regulation: affective, cognitive, and social consequences. Psychophysiology. 2002; 39:281-91. | Article | PubMed

13. Goleman D. Emotional intelligence. New York, NY: Bantam Books. 1995.

14. Bar-On R and Parker J. D. BarOn emotional quotient inventory: Youth version. Technical manual. New York: Multi-Health Systems. 2000. I Pdf

15. Bar-On R. The emotional quotient inventory (EQ-i): A test of emotional intelligence. Toronto. Canada: Multi-Health Systems. 1997. 
16. Schutte N. S, Malouff J. M, Thorsteinsson E. B, Bhullar N and Rooke S. E. A meta-analytic investigation of the relationship between emotional intelligence and health. Personality and Individual Differences. 2007; 42:921-933. | Article

17. Mandler G. A Constructivist Theory of Emotion. Hillsdale, NJ: Lawrence Eribaum Associates. 1990

18. Martins A, Ramalho $\mathrm{N}$ and Morin E. A comprehensive meta-analysis of the relationship between emotional intelligence and health. Personality and Individual differences. 2010; 49:554-564. | Article

19. Centers for Disease Control and Prevention: Chronic disease prevention and health promotion. 2014. I Website

20. Centers for Disease Control and Prevention (CDC): Targeting the Nation's Leading Killer At A Glance. 2014. | Website

21. US Department of Health and Human Services. The health consequences of smoking- 50 years of progress: A report of the surgeon general. Atlanta, GA: US Department of Health and Human Services, Centers for Disease Control and Prevention, National Center for Chronic Disease Prevention and Health Promotion, Office on Smoking and Health. 2014; 17. | Pdf

22. US Department of Health and Human Services. Preventing tobacco use among youth and young adults: A report of the Surgeon General. Atlanta, GA: US Department of Health and Human Services, Centers for Disease Control and Prevention, National Center for Chronic Disease Prevention and Health Promotion, Office on Smoking and Health. 2012; 2.

23. Trinidad D. R and Johnson C. A. The association between emotional intelligence and early adolescent tobacco and alcohol use. Personality and Individual Differences. 2002; 32:95-105. | Article

24. Trinidad DR, Unger JB, Chou CP, Azen SP and Johnson CA. Emotional intelligence and smoking risk factors in adolescents: interactions on smoking intentions. J Adolesc Health. 2004; 34:46-55. | Article | PubMed

25. Powell KE, Caspersen CJ, Koplan JP and Ford ES. Physical activity and chronic diseases. Am J Clin Nutr. 1989; 49:999-1006. I PubMed

26. Salvatoni A, Cardani R, Biasoli R, Salmaso M, De Paoli A and Nespoli L. Physical activity and diabetes. Acta Biomed. 2005; 76 Suppl 3:85-8. I PubMed

27. Thune I and Furberg AS. Physical activity and cancer risk: dose-response and cancer, all sites and site-specific. Med Sci Sports Exerc. 2001; 33:S530-50. | Article | PubMed

28. Centers for Disease Control and Prevention. Facts about physical activity. 2014. | Website

29. Li G. S. F, Lu F. J and Wang, A. H. H. Exploring the relationships of physical activity, emotional intelligence and health in Taiwan college students. Journal of Exercise Science \& Fitness. 2009; 7:55-63. | Article

30. Omar Dev R. D, Ismail I. A, Omar-Fauzee M. S, Abdullah M. C and Geok S. K. Emotional intelligence as a potential underlying mechanism for physical activity among Malaysian adults. American Journal of Health Sciences (AJHS). 2012; 3:211-222. | Article

31. Bhochhibhoya A, Branscum P, Taylor E. L and Hofford C. Exploring the relationships of physical activity, emotional intelligence, and mental health among college Students. American Journal of Health Studies. 2014; 29:191-197. | Article

32. Geliebter $A$ and Aversa A. Emotional eating in overweight, normal weight, and underweight individuals. Eat Behav. 2003; 3:341-7. | Article I PubMed

33. Van Strien T, Schippers GM and Cox WM. On the relationship between emotional and external eating behavior. Addict Behav. 1995; 20:585-94. | Article | PubMed

34. Pinaquy S, Chabrol H, Simon C, Louvet JP and Barbe P. Emotional eating, alexithymia, and binge-eating disorder in obese women. Obes Res. 2003; 11:195-201. | Article | PubMed

35. Centers for Disease Control and Prevention. Alcohol-related disease impact (ARDI). Atlanta, GA. 2008.

36. Rehm J, Gmel G, Sempos CT and Trevisan M. Alcohol-related morbidity and mortality. Alcohol Res Health. 2003; 27:39-51. | Pdf | PubMed
37. Schiff ER. Hepatitis C and alcohol. Hepatology. 1997; 26:39S-42S. | Article | PubMed

38. Hingson RW, Heeren T and Winter MR. Age at drinking onset and alcohol dependence: age at onset, duration, and severity. Arch Pediatr Adolesc Med. 2006; 160:739-46. | Article | PubMed

39. Camatta CD and Nagoshi CT. Stress, depression, irrational beliefs, and alcohol use and problems in a college student sample. Alcohol Clin Exp Res. 1995; 19:142-6. | Article | PubMed

40. Stockwell T. Stress and alcohol. Stress Medicine. 1985; 1:209-215.

41. Qualter P, Gardner K. J and Whiteley H. E. Emotional intelligence: Review of research and educational implications. Pastoral Care in Education. 2007; 25:11-20. | Article

42. Claros $E$ and Sharma M. The relationship between emotional intelligence and abuse of alcohol, marijuana, and tobacco among college students. Dissertation Abstracts International. 2010; 71. | Pdf

43. Brackett M. A, Mayer J. D and Warner R. M. Emotional intelligence and its relation to everyday behaviour. Personality and Individual Differences. 2004; 36:1387-1402. | Article

\section{Citation:}

Bhochhibhoya A and Branscum P. Emotional intelligence: a place in public health promotion and education.

Paediatr Health. 2015; 3:2.

http://dx.doi.org/10.7243/2052-935X-3-2 